\title{
Isolation of Stigmasterol and $\beta$-Sitosterol from the dichloromethane extract of Rubus suavissimus
}

\author{
*Venkata Sai Prakash Chaturvedula, Indra Prakash \\ The Coca-Cola Company, Organic Chemistry Department, Global Research and Development, One Coca-Cola Plaza, \\ Atlanta, GA 30313, USA
}

\begin{abstract}
Purification of the dichloromethane $\left(\mathrm{CH}_{2} \mathrm{Cl}_{2}\right)$ fraction of the aqueous extract of Rubus suavissimus resulted in the isolation of two sterols namely stigmasterol and $\beta$-sitosterol. The structures of the isolated compounds were characterized on the basis of extensive spectral data (1D and 2D NMR; and MS) and in comparison with their literature data.
\end{abstract}

Key Words: Rosaceae, Sterols, Purification, NMR, MS, Structure elucidation.

\section{INTRODUCTION}

Rubus suavissimus S. Lee belongs to the genus Rubus belongs to the flowering plants in the rose family, Rosacea (subfamily Rosoideae). Raspberries, blackberries, and dewberries are widely distributed members of this genus. $R$. suavissimus is a perennial shrub grows widely grown in Guang-xi and Guangdong, China (Koh et al., 2009). The leaves of $R$. suavissimus are used to make beverage leaf tea by the local residents of China due to its intensely sweet flavor, which is known as tiancha in Chinese or Chinese sweet tea. Previous phytochemical studies of this plant mainly showed the presence of diterpene and triterpene glycosides as well as phenolic compounds (Gao et al., 1985; Wang and Lu, 2007; Sugimoto et al., 2001). The major constituent of this plant is the sweet diterpenoid glycoside rubusoside with an aglycone moiety belongs to the class of the diterpene, ent-13-hydroxykaur-16-en-19oic acid, known as steviol (Brandle et al., 1998). As a part of our research to discover natural sweeteners, we have recently reported several ditepene glycosides from $S$. rebaudiana and $R$. suavissimus (Chaturvedula et al., 2011 a-g), triterpene glycosides

\footnotetext{
*Corresponding Author:

Venkata Sai Prakash Chaturvedula, Technical Expert

Organic Chemistry Department

Global Research and Development

One Coca-Cola Plaza, The Coca-Cola Company

Atlanta, GA 30313, USA.

E-mail: vchaturvedula@coca-cola.com

Contact No.: +1-404-676-9257
}

from Siraitia grosvenorii (Chaturvedula and Prakash., $2011 \mathrm{~h}$ ) and phenolic glycosides from R. suavissimus (Chaturvedula et al., 2012).

This paper describes the isolation and structure elucidation of the two sterol components 1-2 (Figure 1) on the basis of extensive spectroscopic and in comparison of their physical and spectral properties reported from the literature.

\section{MATERIALS AND METHODS}

Melting points were measured using a SRS Optimelt MPA 100 instrument and are uncorrected. Optical rotations were recorded using a Rudolph Autopol V at $25^{\circ} \mathrm{C}$ and NMR spectra were acquired on a Varian Unity Plus $600 \mathrm{MHz}$ instrument using standard pulse sequences at ambient temperature. Chemical shifts are given in $\delta$ (ppm), and coupling constants are reported in $\mathrm{Hz}$. HRMS data was generated with a Thermo LTQ Orbitrap Discovery mass spectrometer in the positive positive ion mode electrospray. Instrument was mass calibrated with a mixture of Ultramark 1621, MRFA [a peptide], and caffeine immediately prior to accurate mass measurements of the samples. Samples were diluted with water:acetonitrile:methanol (1:2:2) and prepared a stock solution of $50 \mu \mathrm{l}$ concentration for each sample. Each sample $(25 \mu \mathrm{l})$ was introduced via infusion using the onboard syringe pump at a flow injection rate of $120 \mu \mathrm{l} / \mathrm{min}$. Low pressure chromatography 
Table 1: ${ }^{1} \mathrm{H}$ and ${ }^{13} \mathrm{C}$ NMR chemical shift values for Stigmasterol (1) and $\beta$-Sitosterol (2) recorded in $\mathrm{CDCl}_{3^{\mathrm{a}-c}}$.

\begin{tabular}{|c|c|c|c|c|}
\hline \multirow[t]{2}{*}{ Position } & \multicolumn{2}{|l|}{1} & \multicolumn{2}{|l|}{2} \\
\hline & ${ }^{1} \mathbf{H}$ & ${ }^{13} \mathrm{C}$ & ${ }^{1} \mathbf{H}$ & ${ }^{13} \mathrm{C}$ \\
\hline 1 & & 37.6 & & 37.5 \\
\hline 2 & & 32.1 & & 31.9 \\
\hline 3 & $3.51(\mathrm{tdd}, 1 \mathrm{H}, J=4.5,4.2,3.8 \mathrm{~Hz})$ & 72.1 & $3.53(\mathrm{tdd}, 1 \mathrm{H}, J=4.5,4.2,3.8 \mathrm{~Hz})$ & 72.0 \\
\hline 4 & & 42.4 & & 42.5 \\
\hline 5 & $5.31(\mathrm{t}, 1 \mathrm{H}, J=6.1 \mathrm{~Hz})$ & 141.1 & $5.36(\mathrm{t}, 1 \mathrm{H}, J=6.4 \mathrm{~Hz})$ & 140.9 \\
\hline 6 & & 121.8 & & 121.9 \\
\hline 7 & & 31.8 & & 32.1 \\
\hline 8 & & 31.8 & & 32.1 \\
\hline 9 & & 50.2 & & 50.3 \\
\hline 10 & & 36.6 & & 36.7 \\
\hline 11 & & 21.5 & & 21.3 \\
\hline 12 & & 39.9 & & 39.9 \\
\hline 13 & & 42.4 & & 42.6 \\
\hline 14 & & 56.8 & & 56.9 \\
\hline 15 & & 24.4 & & 26.3 \\
\hline 16 & & 29.3 & & 28.5 \\
\hline 17 & & 56.2 & & 56.3 \\
\hline 18 & & 40.6 & & 36.3 \\
\hline 19 & $0.91(\mathrm{~d}, 3 \mathrm{H}, J=6.2 \mathrm{~Hz})$ & 21.7 & $0.93(\mathrm{~d}, 3 \mathrm{H}, J=6.5 \mathrm{~Hz})$ & 19.2 \\
\hline 20 & $4.98(\mathrm{~m}, 1 \mathrm{H})$ & 138.7 & & 34.2 \\
\hline 21 & $5.14(\mathrm{~m}, 1 \mathrm{H})$ & 129.6 & & 26.3 \\
\hline 22 & & 46.1 & & 46.1 \\
\hline 23 & & 25.4 & & 23.3 \\
\hline 24 & $0.83(\mathrm{t}, 3 \mathrm{H}, J=7.1 \mathrm{~Hz})$ & 12.1 & $0.84(\mathrm{t}, 3 \mathrm{H}, J=7.2 \mathrm{~Hz})$ & 12.2 \\
\hline 25 & & 29.6 & & 29.4 \\
\hline 26 & $0.82(\mathrm{~d}, 3 \mathrm{H}, J=6.6 \mathrm{~Hz})$ & 20.2 & $0.83(\mathrm{~d}, 3 \mathrm{H}, J=6.4 \mathrm{~Hz})$ & 20.1 \\
\hline 27 & $0.80(\mathrm{~d}, 3 \mathrm{H}, J=6.6 \mathrm{~Hz})$ & 19.8 & $0.81(\mathrm{~d}, 3 \mathrm{H}, J=6.4 \mathrm{~Hz})$ & 19.6 \\
\hline 28 & $0.71(\mathrm{~s}, 3 \mathrm{H})$ & 18.9 & $0.68(\mathrm{~s}, 3 \mathrm{H})$ & 19.0 \\
\hline 29 & $1.03(\mathrm{~s}, 3 \mathrm{H})$ & 12.2 & $1.01(\mathrm{~s}, 3 \mathrm{H})$ & 12.0 \\
\hline
\end{tabular}

was performed on a Biotage Flash system using a $\mathrm{C}$ 18 cartridge $(40+\mathrm{M}, 35-70 \mu \mathrm{m})$. TLC was performed on Baker $\mathrm{Si}-\mathrm{C}_{18} \mathrm{~F}$ plates and identification of the spots on the TLC plate was carried out by spraying $10 \%$ $\mathrm{H}_{2} \mathrm{SO}_{4}$ in $\mathrm{EtOH}$ and heating the plate at about $80^{\circ} \mathrm{C}$.

\section{Plant Material}

The commercial sample consisting of the aqueous extract of the leaves of $R$. suavissimus was purchased from Chengdu Biopurify Phytochemicals, China. The plant material was identified by Professor Weiping He, Natural Plant Scientific Institute, Guangdong Ocean University, Guangxi, China and a voucher specimen was deposited at The Coca Cola Company, No. VSPC-3166-68.

\section{Isolation}

The aqueous extract of the leaves of R. suavissimus (10 g) was suspended in $100 \mathrm{ml}$ water and extracted successively with $n$-hexane $(3 \times 100 \mathrm{ml}), \mathrm{CH}_{2} \mathrm{Cl}_{2}(3 \times$ $100 \mathrm{ml})$ and $n-\mathrm{BuOH}(2 \times 100 \mathrm{ml})$. The $\mathrm{CH}_{2} \mathrm{Cl}_{2}$ layer was concentrated under vacuum furnished a residue $(1.5 \mathrm{~g})$ which was purified on a Biotage flash chromatography system using C-18 (100 g) column (solvent system: gradient from 80-20 $\mathrm{MeOH}$-water to $100 \% \mathrm{MeOH}$ at $60 \mathrm{ml} / \mathrm{min}$. detection at UV 210 $\mathrm{nm}$ ) for $40 \mathrm{~min}$. Fractions $48-52$ and 55-60 were combined to get residues $0.25 \mathrm{~g}$ and $0.32 \mathrm{~g}$ respectively, which on repeated purification using the gradient $80-100 \% \mathrm{MeOH}$-water at $30 \mathrm{ml} / \mathrm{min}$ for 40 min resulted stigmasterol (1, $65 \mathrm{mg})$, and $\beta$ sitosterol $(2,70 \mathrm{mg})$, respectively. 


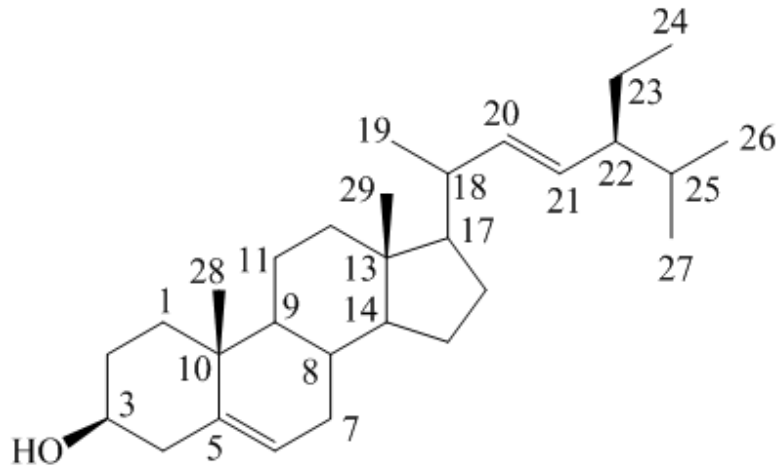

Stigmasterol (1)

Figure 1: Structure of Stigmasterol (1) and $\beta$-Sitosterol (2).

\section{Identification of Stigmasterol and $\beta$-Sitosterol}

Stigmasterol (1): White powder (65 mg); mp: 174$176{ }^{\circ} \mathrm{C}$; ${ }^{1} \mathrm{H}$ NMR $\left(\mathrm{CDCl}_{3}, 600 \mathrm{MHz}\right)$ : see Table $1 ;{ }^{13} \mathrm{C}$ NMR ( $\left.\mathrm{CDCl}_{3}, 150 \mathrm{MHz}\right)$ : see Table 1; MS ( $\left.\mathrm{m} / \mathrm{z}\right): 412$ $[\mathrm{M}+], 394,351,314,300,271,229,213,55$.

$\beta$-Sitosterol (2): White powder (70 mg); mp: 134$135^{\circ} \mathrm{C}$; ${ }^{1} \mathrm{H}$ NMR $\left(\mathrm{CDCl}_{3}, 600 \mathrm{MHz}\right)$ : see Table $1 ;{ }^{13} \mathrm{C}$ NMR ( $\left.\mathrm{CDCl}_{3}, 150 \mathrm{MHz}\right)$ : see Table 1; MS $(\mathrm{m} / \mathrm{z})$ : 414(M+), 396, 339, 325, 310, 298, 257, 227, 140, 139, $125,97,71,57$.

\section{RESULTS AND DISCUSSION}

Compound $\mathbf{1}$ was isolated as a white powder. The mass spectral data of the compound gave a molecular formula $\mathrm{C}_{29} \mathrm{H}_{48} \mathrm{O}$, which was supported by the ${ }^{13} \mathrm{C}$ NMR spectral data. ${ }^{1} \mathrm{H}$ NMR spectra of Compound 1 showed the presence of two methyl sinlgets at $\delta$ 0.71, and 1.03; three methyl doublets that appeared at $\delta 0.80,0.82$, and 0.91 ; and a methyl triplet at $\delta 0.83$. Compound 1 also showed protons at $\delta 4.98,5.14$, and 5.31 suggesting the presence of three protons corresponding to that of a trisubstituted and a disubstituted olefinic bond. Liebermann-Burchard reaction indicated compound $\mathbf{1}$ is having a sterol skeleton (Kandati et al., 2012; Raju et $a l ., 2012)$. The proton corresponding to the $\mathrm{H}-3$ of a sterol moiety was appeared as a triplet of doublet of doublets at $\delta 3.51$. The ${ }^{1} \mathrm{H}$ and ${ }^{13} \mathrm{C}$ NMR values for all the protons and carbons were assigned on the basis of COSY, HMQC and HMBC correlations and were given in Table 1 . The above spectral data supported the presence of sterol skeleton having a

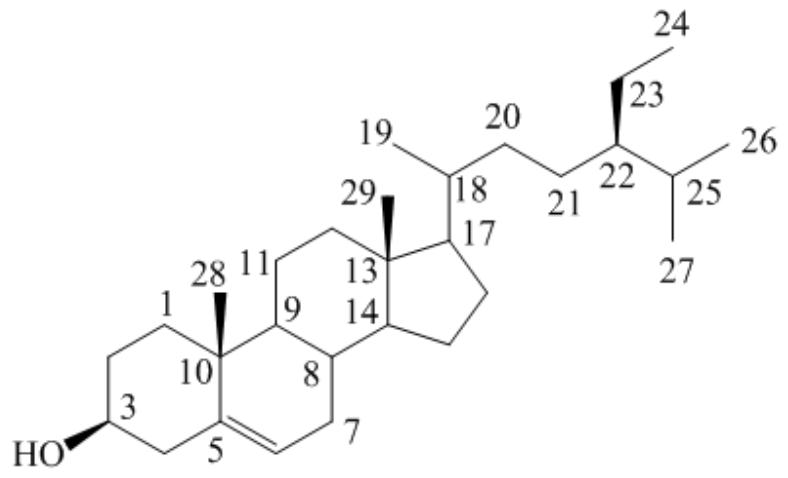

$\beta$-Sitosterol (2)

hydroxyl group at C-3 position with two double bonds at C-5/C-6 and C-20/C-21 with six methyl groups which was supported by the key COSY and HMBC correlations as shown in Figure 2. Thus, the structure of $\mathbf{1}$ was assigned as the known compound stigmasterol. The physical and spectral data are consistent to the reported literature values (Habib et al., 2007; Jamal et al., 2009; Moghaddam et al., 2007) of stigmasterol.

Compound 2 was also isolated as a white powder and its mass spectral data suggested the molecular formula as $\mathrm{C}_{29} \mathrm{H}_{50} \mathrm{O}$. Compound 2 also showed positive Liebermann-Burchard reaction indicated its sterol nature as in 1 . The ${ }^{1} \mathrm{H}$ NMR spectra of compound 2 showed the presence of six methyl signalss that appeared as two methyl sinlgets at $\delta$ 0.68 , and 1.01; three methyl doublets that appeared at $\delta 0.81,0.83$, and 0.93; and a methyl triplet at $\delta$ 0.84 ; same as 1 . The ${ }^{1} \mathrm{H}$ NMR spectra of compound 2 also showed one olefinic proton at $\delta 5.36$ instead of three in $\mathbf{1}$. The absence of protons corresponding to the double bond between C-20/C-21 in compound 2 together with the appearance of mass spectral data which showed 2 amu more than 1 suggested the presence of a trisubstituted double bond at C-5/C-6 in its structure. The ${ }^{1} \mathrm{H}$ NMR spectra of compound 2 showed a proton corresponding to the proton connected to the C-3 hydroxy group which appeared as a triplet of doublet of doublets at $\delta 3.53$. The ${ }^{13} \mathrm{C}$ NMR together with COSY, HMQC and HMBC showed twenty nine carbon signal including six methyls, eleven methylenes, ten methane and 


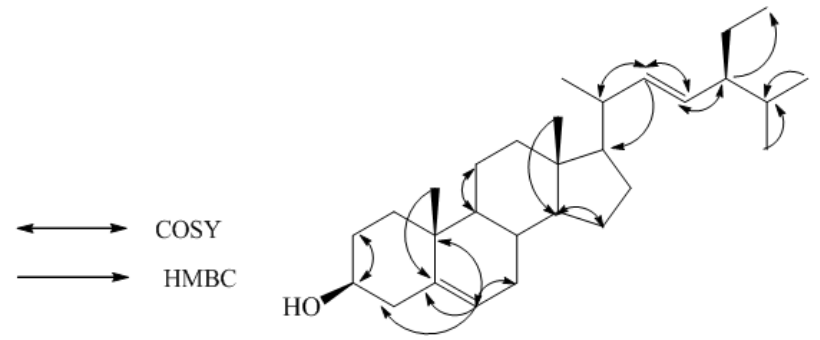

Stigmasterol (1)

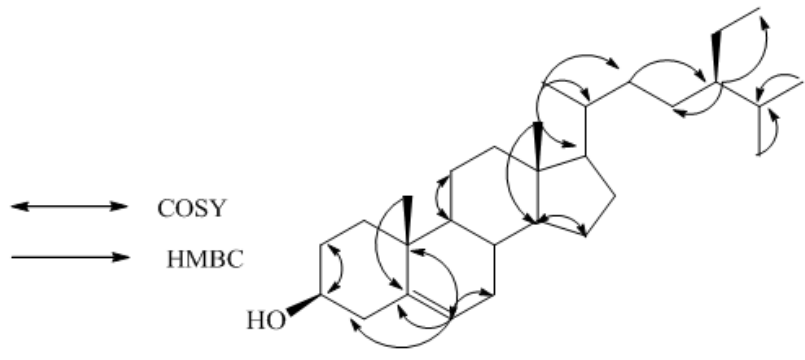

$\beta$-Sitosterol (2)

Figure 3: Key COSY and HMBC Correlations of $\beta$-Sitosterol (2). three quaternary carbons. Thus, the structure of $\mathbf{2}$ was assigned as $\beta$-sitosterol that was consistent to the reported literature values (Habib et al., 2007; Jamal et al., 2009) and was further supported by the key COSY and HMBC correlations as shown in Figure 3.

\section{CONCLUSION}

Two sterols were isolated from the commercial extract obtained from the leaves of $R$. suavissimus obtained from Chengdu Biopurify Phytochemicals Limited, China. The structures of the isolated new compounds were identified as stigmasterol (1), and $\beta$-sitosterol (2) on the basis of spectroscopic and by comparing their physical properties reported in the literature. The complete ${ }^{1} \mathrm{H}$ and ${ }^{13} \mathrm{C}$ NMR spectral assignments of the two isolated compounds were made based on COSY, HSQC, HMBC, and MS/MS spectroscopic data.

\section{ACKNOWLEDGEMENT}

We wish to thank Chengdu Biopurify Phytochemicals Limited, China for providing the Rubus suavissimus aqueous extract.

\section{REFERENCES}

Brandle, J.E., Starrratt, A.N, Gijen, M. (1998). Stevia rebaudiana: Its Agricultural, Biological and Chemical Properties. Canadian Journal of Plant Sciences 78: 527-536. [DOI]

Chaturvedula, V.S.P., Mani, U., Prakash, I. (2011a). Diterpene Glycosides from Stevia rebaudiana. Molecules, 16: 3552-3562. [DOI]

Chaturvedula, V.S.P., Prakash, I. (2011b). A New Diterpenoid Glycoside from Stevia rebaudiana. Molecules, 16: 2937-2943. [DOI]

Chaturvedula, V.S.P., Prakash, I. (2011c). Structures of the Novel Diterpene Glycosides from Stevia rebaudiana. Carbohydrate Research, 346: 10571060. [DOI]

Chaturvedula, V.S.P., Rhea, J., Milanowski, D., Mocek, U., Prakash, I. (2011d). Two Minor Diterpene Glycosides from the Leaves of Stevia rebaudiana. Natural Product Communications, 6: 175-178.
Chaturvedula, V.S.P., Clos, J.F., Rhea, J., Milanowski, D., Mocek, U., DuBois, G.E., Prakash, I. (2011e). Minor Diterpene Glycosides from the Leaves of Stevia rebaudiana. Phytochemistry Letters, 4: 209-212. [DOI]

Chaturvedula, V.S.P., Prakash, I. (2011f). Additional Minor Diterpene Glycosides from Stevia rebaudiana. Natural Product Communications, 6: 1059-1062.

Chaturvedula, V.S.P., Mani, U., Prakash, I. (2011g). Structures of the Novel $\alpha$-Glucosyl Linked Diterpene Glycosides from Stevia rebaudiana. Carbohydrate Research, 346: 2034-2038. [DOI]

Chaturvedula, V.S.P., Prakash, I. (2011h). Cucurbitane glycosides from Sitaitia grosvenorii. Journal of Carbohydrate Chemistry, 30: 16-26.

Chaturvedula, V.S.P., Prakash, I. (2012). Chemical Constituents from the Polar Fraction of Rubus suavissimus. Organic Chemistry: Current Research, 1: 101.

Gao, F., Chen, F., Tanaka, T., Kasai, R., Seto, T., Tanaka, O. (1985) $19 \alpha-$ Hydroxyursane-type Triterpene Glucosyl Esters from the Roots of Rubus suavissimus S. Lee. Chemical and Pharmaceutical Bulletin 33: 37-40. [DOI]

Habib, M.R., Nikkon, F., Rahman, M., Haque, M.E., Karim, M.R. (2007) Isolation of Stigmasterol and b-Sitosterol from Methanolic Extract of Root Bark of Calotropis gigantean (Linn), Pakistan Journal of Biological Sciences. 10: 4174-4176.

Jamal, A.K., Yaacob, W.A., Din, L.B. (2009). A Chemical Study on Phyllanthus columnaris, European Journal of Scientific Research, 28: 76-81.

Kandati, V., Govardhan, P., Reddy, C.S., Nath, A.R., Reddy, R.R. (2012). Invitro and in-vivo anti-inflammatory activity of Andrographis serpyllifolia (Rottl. Ex Vahl.) Wt. International Current Pharmaceutical Journal 1: 199-204

Koh, G.Y., Chou, G., Liu, Z. (2009) Purification of a water extract of Chinese sweet tea plant (Rubus suavissimus S. Lee) by alcohol preparation. Journal of Agricultural and Food Chemistry, 57: 5000-5006. [DOI]

Moghaddam, F.M., Farimani, M.M., Salahvarzi, S., Amin, G. (2006). Chemical Constituents of Dichloromethan Extract of Cultivated Satureja khuzistanica, Evidence-Based Complementary and Alternative Medicine, 4: 95-98.

Raju, V.H., Ganapaty, S., Prasanna, S.S., Vijaya, G.J., Kishore, P.S., Asif, A.K. (2012). Phytochemical and pharmacological evaluation of Tragia cannabina for anti-inflammatory activity, International Current Pharmaceutical Journal 1: 213-216.

Sugimoto, N., Kikuchi, H., Yamazaki, T., Maitani, T. (2001). Polyphenolic Constituents from the Leaves of Rubus suavissimus. Natural Medicines (Tokyo, Japan) 55: 219.

Wang, J., Lu, H. (2007). Chemical constituents of Rubus suavissimus S. Lee. Zhongyaocai 30: 800-802. 